\title{
Surgical presentation of small bowel lymphoma in adult coeliac disease
}

\author{
P. J. Finan \\ F.R.C.S.
}

\author{
M. R. THOMPSON \\ F.R.C.S.
}

Bristol Royal Infirmary, Bristol BS2 $8 \mathrm{HW}$

\begin{abstract}
Summary
A case of perforation of a small bowel lymphoma in a patient with coeliac disease is reported. Postoperative management was complicated by a large protein and fluid loss from the small bowel, rapidly controlled by treatment with corticosteroids. Attention is drawn, by briefly reviewing 11 other cases, to the ways in which small bowel lymphoma in patients with coeliac disease may present to the surgeon. Most patients who develop this complication of coeliac disease will die within 6 months of the diagnosis of small bowel lymphoma. Attention is drawn in this case to the rapidity with which the tumour grew and became disseminated.
\end{abstract}

\section{Introduction}

The association of small bowel lymphoma with established coeliac disease was first described by Gough, Read and Naish (1962) and has since been confirmed by Harris et al. (1967) and Austad et al. (1967). The development of small bowel lymphoma in patients with coeliac disease frequently involves the surgeon, both in establishing the diagnosis and in subsequent management. This report records one way in which small bowel lymphoma may present and also briefly reviews the surgical presentation of 11 similar cases.

\section{Case report}

A 62-year-old woman presented in December 1977 with a 3-month history of steatorrhoea and a weight loss of $11 \mathrm{~kg}$. Her son was already being treated for coeliac disease.

On examination she was thin, she had a smooth tongue, peripheral oedema and slight hepatomegaly.

Investigations (normal ranges are given in parenthesis) revealed a haemoglobin of $13.3 \mathrm{~g} / \mathrm{dl}$; MCV $107 \mathrm{ff}$; a peripheral film showed macrocytosis; serum folate $2.6 \mathrm{mg} / \mathrm{l}(3-10)$; red cell folate $81 \mathrm{mg} / \mathrm{l}$ (160-640); serum vitamin $B_{12} 246 \mathrm{ng} / \mathrm{l}$ (160-925); total serum protein $57 \mathrm{~g} / \mathrm{l}$; serum albumin $28 \mathrm{~g} / \mathrm{l}$ (35-55) and a corrected serum calcium of $2.20 \mathrm{mmol} / 1$ (2.25-2.65). Her HLA type was A1, AW23, B8,
BW49. A 3-day faecal fatty acid was $41.5 \mathrm{mmol} /$ day $(0-15)$ and $4.8 \%$ (normal $>23 \%$ ) of a $5-\mathrm{g}$ oral dose of xylose was excreted in the urine in $5 \mathrm{hr}$.

A small bowel meal showed flocculation and segmentation of the barium with widening of the small bowel lumen, coarsening of the valvulae conniventes and some mucosal oedema.

Jejunal biopsy showed total villous atrophy consistent with coeliac disease but no evidence of malignancy.

On the basis of these investigations and the family history a diagnosis of coeliac disease was made and she was commenced on a gluten-free diet in January 1978.

Clinically there was only a poor response to gluten withdrawal and 2 weeks later she suddenly developed severe lower abdominal pain. On examination there was evidence of generalized peritonitis. An erect abdominal film showed free gas under the diaphragm.

After resuscitation, operation revealed generalized peritonitis secondary to a perforation of the small bowel $12 \mathrm{~cm}$ from the ileo-caecal valve. The perforation was well circumscribed and not obviously associated with any underlying disease.

A careful search revealed no macroscopic evidence of intra-abdominal malignancy at this time.

A $15 \mathrm{~cm}$ length of ileum containing the perforation was resected and both proximal and distal ends brought out through the lower end of the wound as a double barrelled ileostomy. A primary anastomosis was not attempted in view of the patient's general condition.

Histological examination revealed a poorly differentiated diffuse lymphocytic lymphoma with extension through all layers of the bowel wall. The edges of the resection were well clear of tumour and the surrounding mucosa showed only partial villous atrophy, a slight improvement on the initial jejunal biopsy.

The postoperative management was difficult, requiring careful fluid balance and parenteral nutrition. The amount of ileal fluid lost postoperatively rose to 7 litre $3 /$ day with a protein content 
of $10 \mathrm{~g} / 1$ (Fig. 1). Thus the protein loss from the ileum reached $70 \mathrm{~g} /$ day. Some of this fluid was returned to the small bowel via the distal limb of the ileostomy. This was tolerated well and there was no diarrhoea.

Hydrocortisone was introduced on the 6th postoperative day to control the ileal effluent. The volume rapidly fell to one litre/day and the concentration of protein in the effluent was also greatly reduced (Fig. 1). The development of a chest infection with Mycoplasma pneumoniae was associated with a transient rise in the fluid loss but this fell to its former level when the patient was treated with intravenous tetracycline.

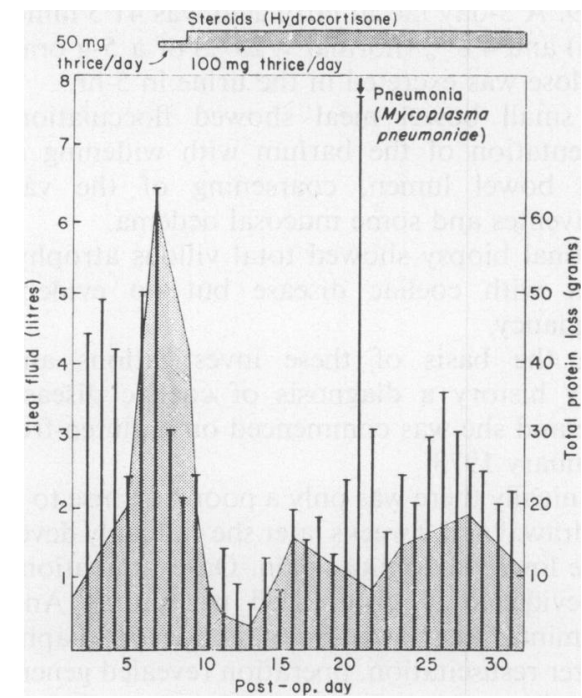

FIG. 1. Surgical presentation of small bowel lymphoma in adult coeliac disease.

On parenteral nutrition her general condition improved with a gradual increase in serum albumin $(38 \mathrm{~g} / \mathrm{l})$ and a disappearance of the peripheral oedema. However, 6 weeks after the initial operation, following repeated prolapse of the stoma, a second operation was performed to close the ileostomy. On this occasion at least 8 discrete tumours were noted on the mesenteric border of the small bowel. One of these tumours was resected and subsequently shown to be a malignant lymphoma.

Following the 2 nd operation she made a rapid recovery. A jejunal biopsy in March 1978, 2 months after starting a gluten-free diet, showed only mild partial villous atrophy which was a marked improvement over the first biopsy. At this stage she was taking $20 \mathrm{mg}$ prednisolone daily. Before discharge on 5 May 1978 she was given a 3-week course of fractionated low dose radiotherapy for the residual small bowel lymphoma.

She was re-admitted 2 wceks later, 14 weeks after the initial perforation, with gross ascites. Despite treatment she rapidly deteriorated and died on $28 \stackrel{\mathrm{Q}}{\mathrm{Q}}$ May 1978. Post-mortem revealed disseminatedc intra-abdominal lymphocytic lymphoma with $\Rightarrow$ numerous deposits throughout the small bowel.

\section{Review of other cases}

Since 1960 to date 11 patients with small bowel $\frac{\overline{\bar{c}}}{\stackrel{5}{(}}$ lymphoma complicating adult coeliac disease have $\varrho$ presented to hospitals in the Bristol district with surgical problems. Six presented with small bowel $\vec{P}$ obstruction ( 2 of these had a perforation of the bowel proximal to the obstruction); 2 presented as $\vec{\omega}$ a free perforation; the remaining 3 patients presented $\stackrel{\Omega}{\circ}$ with an abdominal mass-in 2 of these the diagnosise of small bowel lymphoma was made at post-mortem. Eight of the patients died within 6 weeks of the diagnosis being made; of the remaining 3 patients, $\dot{\circ}$ 2 survived for 6 months and one for 9 months.

\section{Discussion}

A diagnosis of coeliac disease is usually made $\stackrel{\text { ? }}{?}$ when a patient with malabsorption, who has been $\vec{\square}$ shown to have a flat jejunal mucosa with villous $\mathbb{\infty}$ atrophy, responds to withdrawal of gluten from the diet both clinically and by improvement of the $\frac{3}{0}$ mucosal architecture.

Although in this case the patient died withing $4 \overrightarrow{0}$ months of presentation a diagnosis of coeliac diseaseo can reasonably be made.

The association of small bowel lymphoma ando malabsorption was first noted by Fairley and Mackie (1937). Gough et al. (1962) reported 3 cases of smallo bowel lymphoma developing in established adult $\frac{0}{\varnothing}$ coeliac disease and suggested that this tumour was a $\propto$ complication of the underlying disease. Harris et al. $\overrightarrow{\overrightarrow{0}}$ (1967) confirmed their findings when they reviewed 3 202 cases of coeliac disease in Birmingham. Austad et al. (1967) reported 7 cases as a follow-up to? Gough's initial report.

Harris et al. (1967) also noted the increased incidence of other gastro-intestinal tumours, particu- $\frac{}{3}$ larly carcinoma of the oesophagus. Adult coeliacdisease may also be complicated by adenocarcinoma of the small bowel, although surprisingly infrequently (Kenwright, 1972; Petreshock, Pessah and 은 Menachemi, 1975). These tumours are most $D$ frequently located in the jejunum and proximal ileum.

Austad et al. (1967) stress the importance of investigating new symptoms in patients who have previously been well controlled on a gluten-free diet. $\omega$ These symptoms include fever, weight loss, abdominal pain and a recurrence of initial symp-co toms. A poor initial response to gluten withdrawal may, as in the case reported here, indicate an under-? lying malignancy (Barry and Read, 1973). 
However, these patients may present directly to the surgeon with intestinal obstruction, free small bowel perforation or an abdominal mass. Isaacson and Wright (1978) noted that acute obstruction or perforation preceded by abdominal pain and weight loss was the commonest presentation in 18 patients with small bowel lymphoma, 5 of whom may have had adult coeliac disease before the lymphoma.

Postoperative management in the present case was complicated by a large ileal fluid loss and a protein-losing enteropathy, both of which responded dramatically to treatment with steroids.

The ultimate outlook for these patients at the present time is bleak. The rapidity of the growth and spread of the lymphoma was carefully documented in this case. At the first laparotomy in February there was no macroscopic evidence of lymphoma. Six weeks later there were 8 discrete nodules and after a further 10 weeks, at post-mortem, the lymphoma was widely disseminated throughout the small bowel and mesentery.

\section{Acknowledgments}

We wish to thank $\mathrm{Mr} \mathrm{H}$. K. Bourns for allowing us to report this patient under his care; to the surgeons at the
Bristol Royal Infirmary who had some of the other patients under their care; and to Dr R. E. Barry of the University Department of Medicine for his kind assistance.

\section{References}

Austad, W.I., Cornes, J.S., Gough, K.R., McCarthey, C.F. \& READ, A.E. (1967) Steatorrhea and malignant lymphoma. The relationship of malignant tumors of lymphoid tissue and celiac disease. American Journal of Digestive Diseases, 12, 475.

BARRY, R.E. \& READ, A.E. (1973) Coeliac disease and malignancy. Quarterly Journal of Medicine, (N.S.), 42, 665.

FAIRLEY, N.H. \& MACKIE, F.P. (1937) The clinical and biochemical syndrome in lymphadenoma and allied diseases involving the mesenteric lymph glands. British Medical Journal, 1, 375.

Gough, K.R., ReAD, A.E. \& NaISH, J.M. (1962) Intestinal reticulosis as a complication of idiopathic steatorrhoea. Gut, 3, 232.

Harris, O.D., CoOKe, W.T., Thompson, H. \& Waterhouse, J.A.H. (1967) Malignancy in adult celiac disease and idiopathic steatorrhea. American Journal of Medicine, 42, 899.

IsAACSON, P. \& WRIGHT, D.H. (1978) Intestinal lymphoma associated with malabsorption. Lancet, i, 67.

KenWright, S. (1972) Coeliac disease and small bowel carcinoma. Postgraduate Medical Journal, 48, 673.

Petreshock, E.P., Pessah, M. \& Menachemi, E. (1975) Adenocarcinoma of the jejunum associated with nontropical sprue. American Journal of Digestive Diseases, 20, 796. 